\title{
Natural lighting in the premises of public institutions situated at the ground floors of buildings
}

\author{
Sergey Stetsky ${ }^{1}$ and Kira Larionova ${ }^{1, *}$ \\ ${ }^{1}$ Moscow State University of Civil Engineering, Yaroslavskoe shosse, 26, Moscow, 129337, Russia
}

\begin{abstract}
The article deals with the typical problems of natural lighting in the public premises of different types situated at the ground floors of buildings, in which shops, social institutions, banks and post offices, etc. can be located. The problems of natural lighting of such premises are associated with the use of windows as a screen for various types of information - from advertising billboards to the display of goods, etc. In this case, the efficient area of windows is reduced dramatically. This leads to a decrease in the values of the coefficient of daylight and, consequently, to an increase in the cost of electricity aimed at constant additional interior lighting. The authors suggest an optimum method of balancing the informative and lighting performance of window openings in the premises in question. The results of field studies and decisions about the internal illumination are given to confirm the minimum acceptable window size required to maintain both satisfactory interior lighting and minimum power consumption.
\end{abstract}

\section{Introduction}

For the time being, the requirements for the light environment in premises of public buildings are dictated not only by the level of illumination, needed to perform a determined visual task, but also by levels of lighting comfort and by the physiological visual contact with the outdoor environment. Unfortunately, such as requirement are not strictly fulfilled in modern premises of public institution, which are now widely spread at ground floors of residential buildings.

The main feature in these premises (such as shops, social institutions, banks and post offices, retail stores etc.) is complete denying of natural light role in the environmental physics of these premises.

Such a statement is mainly based on the attitude to natural lighting of interiors of the premises in question. It is a basic contemporary approach to the lighting, that the natural light could be easily combined with the artificial light.

This approach, unfortunately, is wrong. Why should we make large windows and afterwards cover them with blockage of billboard, shelves with goods and mannequins? Such an attitude is very traditional to the public premises in the modern architectural

\footnotetext{
* Corresponding authors: LarionovaKO@mgsu.ru
} 
design. Hence, the aim of this work is to find an optimum relation between the size of clear glazing of windows and the size of shadowing elements over it to ensure both an informative quality of the window openings of public institutions and to ensure the satisfactory amount of indoor natural light. [1-9].

\section{Theoretical backgrounds}

According to the national standards, traditional «codex and Regulations» and modern «Set of Rules» on natural and artificial lighting, used for the time being in Russian Federation $[10,11,12]$.

The design value of daylight factor for side-lit premises is calculated as follows:

$$
\text { D. F. } \cdot \mathrm{S}=\left[\varepsilon_{\mathrm{S}} \cdot \mathrm{q}+\varepsilon_{\mathrm{B}} \cdot \mathrm{K}_{\mathrm{B}} \cdot \mathrm{b}_{\mathrm{f}}\right] \frac{\tau_{\mathrm{G}} \cdot r_{G}}{\mathrm{~K}_{\mathrm{S}}}
$$

Where the shortenings read:

D. F.S - design daylight factor for side-lit premises; sky.

$\varepsilon_{\mathrm{S}}$ - geometric daylight factor for side lighting, which takes into account the light of the

$$
\varepsilon_{\mathrm{S}}=0,01 \cdot n_{1} \cdot n_{2}
$$

where $n_{1}$ and $n_{2}$ are numbers of light rays, coming from the sky vault to a design point, according to the A. M. Daniluk' graphs 1 and 2, based on Moon-Spenser law for a standard «CIE» overcast sky conditions;

$\mathrm{q}$ - the factor, which takes into account an uniform distribution of the sky vault brightness;

$\mathrm{q}=f(\varphi)$, where $« \varphi »$ is an angle between the line from a design point to a centre of a window and the horizontal line, corresponded to a «working plane» level;

$\mathrm{K}_{\mathrm{S}}$ - a spare factor.

$\tau_{\mathrm{G}}$ - a factor, which takes into account a general light penetration through a window;

$r_{G}$-a factor, which takes into account the general increase of daylight factor, due to the light flows, reflected from the walls, floor and ceiling of a premise.

$\varepsilon_{B}, K_{B}, b_{f}-a$ set of factors, which takes into account the shadowing effect of the surrounding development, namely: geometric daylight factor from the opposite buildings, and a factor, taking into account the size and position of the opposite buildings and the color of their finishing.

These factors, for simplicity, are not used in our calculations, as we assume that the opposite-standing development is absent. Hence, the final design formula will take the easiest view:

$$
\text { D. F. } \mathrm{S}=\frac{\varepsilon_{\mathrm{S}} \cdot \mathrm{q} \cdot \tau_{\mathrm{G}} \cdot r_{G}}{\mathrm{~K}_{\mathrm{S}}}
$$

The field and design researches will be based on different height of shading elements in the area of windows in the premises considered.

\section{Field and design studies}

There is a plenty of examples of the premises in question in every large city, say, in Moscow (Figure 1 and Figure 2).

The field study was conducted on one of such objects by the members of «Design of buildings and structures «chair of Moscow State University of Civil engineering». The main working premise of a local drug store was choosing. 
It possessed the following geometric and light-engineering characteristics:

1. The depth of the working premise $\mathrm{L}=6,0 \mathrm{~m}$.

2. The width of the working premise $\mathrm{W}=12,0 \mathrm{~m}$.

3. The height of the working premise $\mathrm{H}=3,6 \mathrm{~m}$.

4. The height of window $\mathrm{H}_{\mathrm{w}}=3,0 \mathrm{~m}$.

5. The width (length) of window $\mathrm{W}_{\mathrm{w}}=12,0 \mathrm{~m}$.

6. Glazing of the window - two-ply, ordinary window glass, $8 \mathrm{~mm}$ thick.

7. Window and sashes framing - steel.

8. Finishing of internal planes: white ceiling, light-grey walls, dark-brown floor.

9. Position of a sill - $0,4 \mathrm{~m}$ over floor.

10. Position of lintel - $0,2 \mathrm{~m}$ below ceiling.

11. Working plane level $-0,8 \mathrm{~m}$ over floor.

12. Design point - on a working plane level, $1 \mathrm{~m}$ from the rear wall.

This set of data, which are partly constant, partly variable makes possible to determine some factors, necessary for design calculation. Hence $-\tau_{G}$ with 2 -ply glazing, steel framing, absence of solar-protective device, etc. for system of side lighting equals to $0,8 \cdot 0,8=$ 0,64 .

- With white ceiling, light grey walls and dark-brown floor finish, the average weighting factor of reflection in the premise can be taken as $\rho_{o}=0,5$;

- Spare factor $\mathrm{K}_{\mathrm{S}}$ equals to 1,2 .

- The value of $r_{G}$ for a design point fquals to 2,0.

In our researches we change the clear glass area, covering the window with shuttering sheets of carton, veneer, wallboard, etc., which plays part of advertising bill boards and shelves with display of goods, etc. Such a shuttering blinded areas vary in height, making the angle of sky-vault observation from a design point different, which leads to a different value of «q» factor. (See Figure 3). The calculations are conducted according Formula (3) I.E. for the case of opposite buildings absence. All the design Factors are put together in Table 1.

The results of the study are shown on Figure 4, on which the graph represents the change of daylight factor values in a design point of the discussed premise in relation with the height of the stuttering blinds over the window glazing. The heights of these shutters equals to 1,0 and $2,0 \mathrm{~m}$. Hence, we are to calculate the daylight factor values for three different cases: with blinding shutters of low height, with medium height and for a completely clear window with no shuttering.

According to $[10,11,12]$, the normative value of daylight factor $« \mathrm{D} . \mathrm{F}_{\cdot_{\mathrm{N}}} »$ for premises of different public buildings varies in the range from 0,5 to $1,5 \%$. Hence, the premises considered satisfy the normative requirements even in the case of minimum area of window glazing. This corresponds to the case 1 with maximum height of shuttering $(2,0 \mathrm{~m})$ and minimum height of clear glazing (see Figure 4).

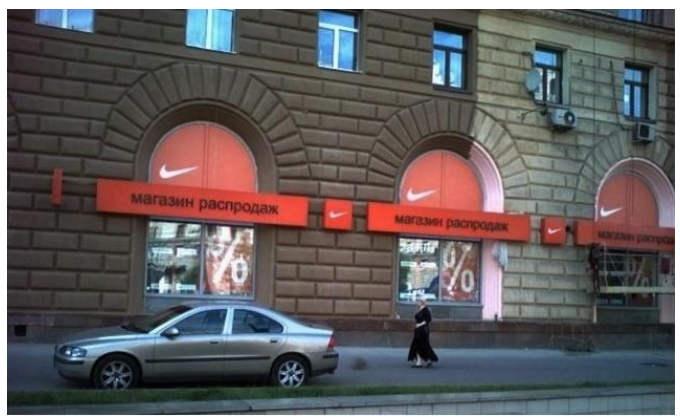

Fig. 1. A shop situated at ground floor of a building. 


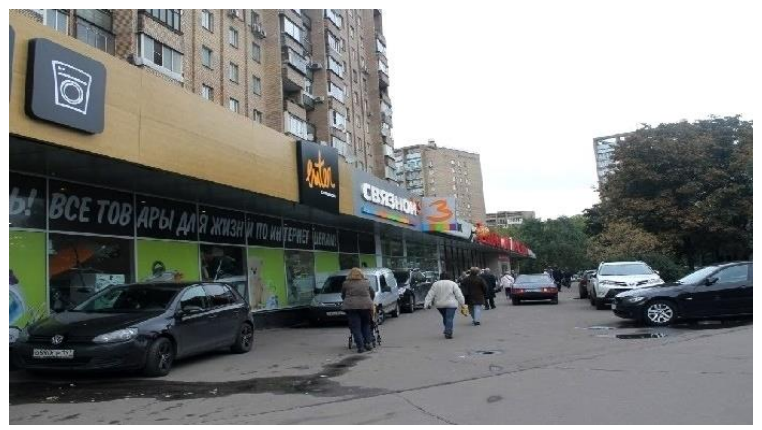

Fig. 2. A shop situated in a single storey block attached to a building.

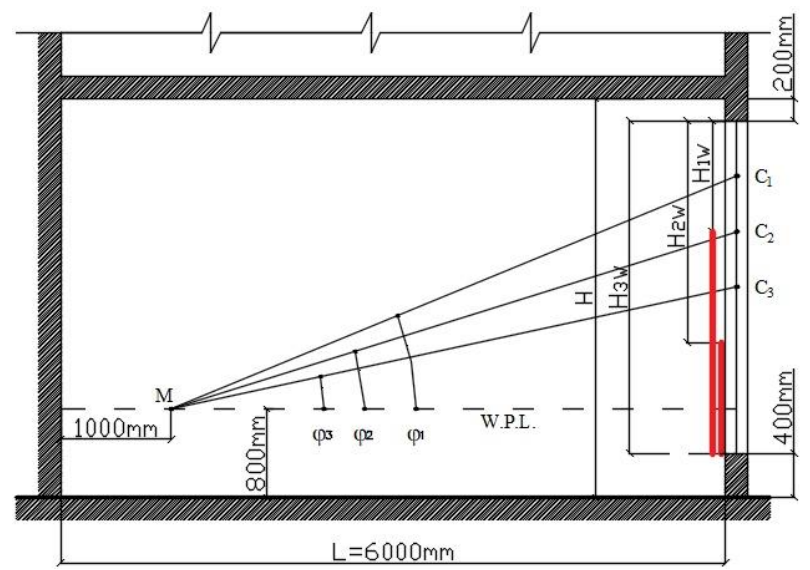

Fig. 3. Fragment of the cross-section of the building with a public premise on the ground floor. Where: $\mathrm{M}$ - a design point, foremost from a window; $\mathrm{C} 1, \mathrm{C} 2, \mathrm{C} 3$ - centers of a clear glass portion, after screening a certain part of a window; $\mathrm{H}_{1 \mathrm{~W}}=1000 \mathrm{~mm} ; \mathrm{H}_{2 \mathrm{~W}}=2000 \mathrm{~mm} ; \mathrm{H}_{3 \mathrm{~W}}=3000 \mathrm{~mm}$; (the full height of an clear window); W.P.L. - working plane level; $\varphi_{1}, \varphi_{2}, \varphi_{3}$, - sky-vault viewing angles.

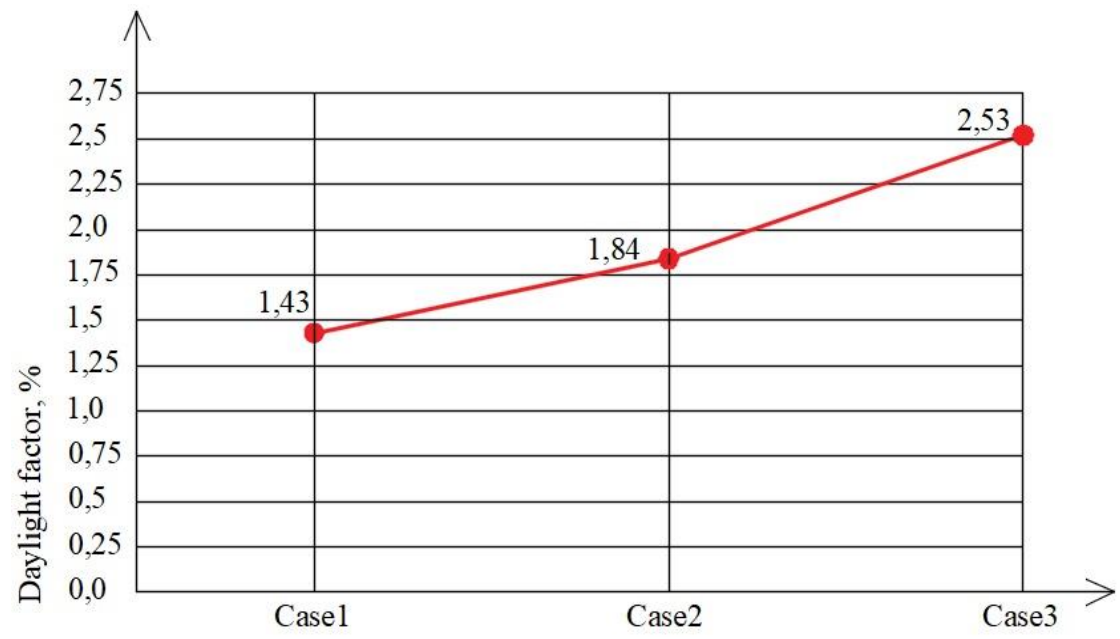

Window area, cases

Fig. 4. The change of daylight factor value in a design point $« M »$ with different area of windows glazing in a premise considered. 
Table 1. Daylight factor values for three cases of windows area.

\begin{tabular}{|c|c|c|c|c|c|c|c|c|c|c|c|c|}
\hline $\mathrm{N}$ & $\begin{array}{c}\text { Case of a } \\
\text { study }\end{array}$ & $\varphi^{0}$ & $\mathrm{q}$ & $\mathrm{n}_{1}$ & $\begin{array}{l}\text { \#of } \\
\text { semicircle }\end{array}$ & $\mathrm{n}_{2}$ & $\varepsilon_{\mathrm{s}}$ & $\tau_{\mathrm{G}}$ & $r_{G}$ & $\mathrm{~K}_{\mathrm{S}}$ & D. F.s & Notes \\
\hline 1 & 2 & 3 & 4 & 5 & 6 & 7 & 8 & 9 & 10 & 11 & 12 & 13 \\
\hline 1 & $\begin{array}{l}\text { Case } 1 \\
\text { Fully clear } \\
\text { glazing }\end{array}$ & $\begin{array}{r}\varphi_{1} \\
24^{\circ}\end{array}$ & 0,77 & 3,5 & 55 & 50 & 1,75 & 0,64 & 2,0 & 1,2 & 1,43 & - \\
\hline 2 & $\begin{array}{l}\text { Case } 2 \\
\text { Glazing with } \\
\text { blinds of } 1,0 \mathrm{~m} \\
\text { height }\end{array}$ & $\begin{array}{c}\varphi_{2} \\
18^{\circ}\end{array}$ & 0,69 & 4,5 & 52 & 55 & 2,5 & 0,64 & 2,0 & 1,2 & 1,84 & - \\
\hline 3 & $\begin{array}{l}\text { Case } 3 \\
\text { Glazing with } \\
\text { blinds of } 2,0 \mathrm{~m} \\
\text { height }\end{array}$ & $\begin{array}{c}\varphi_{3} \\
12^{\circ}\end{array}$ & 0,61 & 6,5 & 50 & 60 & 3,9 & 0,64 & 2,0 & 1,2 & 2,53 & - \\
\hline
\end{tabular}

\section{Conclusions}

1. The study shows that the decrease in values of daylight factor is not linear. The higher the position of a window, the more light rays $\mathrm{n}_{1}$, according to the A. M. Daniluk' graphs, penetrate into the interior. So, increase in the $\mathrm{n}_{1}$ value is much greater, than the decrease in height (or area) of the window in question.

2. Due to the above conclusion, we can state that the area of a window can be easily reduced up to the size, which provides the value of daylight factor not less than $1,0 \%$. Hence, the area of shadowing elements may be taken easily up to $50 \%$ of window height. The displays of goods or advertising billboards in this case are conveniently placed in the bottom portion of window, which corresponds to average height of a human being. The upper part of a window in this case will surely satisfy the requirements for the interior natural lighting.

3. The article represents the «pilot study» stage of the investigations, dealing with the problem in question. The results obtained and conclusions made, force the authors to continue researches upon the stated field of lighting engineering in a series of real object with different characteristics.

\section{References}

1. L. Brotas, M. Witson, Svetotechnika 3, 44-47 (2008)

2. P.R. Terenza, Light research and Technology 18-2, 71-74 (1986)

3. P.R. Terenza, Light research and Technology 12-2, 64-68 (1980)

4. S.V. Stetsky, K.O. Larionova, Scientific Review 15, $42-47$ (2016)

5. E. Neeman, R.G. Hopkinson, Light research and Technology 2-1, 17-27 (1970)

6. S.V. Stetsky, IOP Conference Series: Earth and Environmental Science 90, 012222, 16 (2017)

7. A.K. Soloviev, Light \& Engineering 25-1, 23-30 (2017)

8. V.A. Zemtsov, A.K. Soloview, I.A. Shmarov, Light \& Engineering 25-1, 106-114 (2017)

9. K.O. Larionova, Scientific Review 21, 70-74 (2016)

10. Sanitary rules and standards of Russian Federation SanPin 2.2.1/2.1.1.1278-03

11. Set of Russian Federation Regulations SP 23-102-2003

12. Set of Russian Federation Regulations SP 52.1330.2011 